\title{
A Standard, Knowledge Integrated Consultation Document for Pediatric HIV Information Exchange
}

\author{
Debkumar Patra, MS ${ }^{1 *}$, Jayanta Mukherjee ${ }^{1}$, Arun K. Majumdar ${ }^{1}$, \\ Bandana Majumdar ${ }^{1}$, Sangeeta DasBhattacharya ${ }^{2}$, Soubhik Paul ${ }^{2}$ \\ ${ }^{1}$ Department of Computer Science and Engineering \\ ${ }^{2}$ School of Medical Science and Technology \\ Indian Institute of Technology Kharagpur, Kharagpur - 721302, India
}

Submitted July 2010. Accepted for publication March 2011.

\begin{abstract}
HIV/AIDS is one of life-threatening diseases over which human currently does not have enough control. Study and research on HIV and its prevention are being carried out by different organizations. However, they are mostly area specific, thereby, failing to provide a nation-wide or region-wide overview of HIV infection. One of the major bottlenecks in having a wider study is the lack of interoperability among systems managing HIV patient information. Besides, such lack of interoperability also hinders forming larger HIV care network where telemedicine could be accomplished more effectively. We have addressed this interoperability issue through HL7 clinical document architecture (CDA), a document-based messaging standard for clinical interaction. This article introduces a document architecture that conforms to HL7 CDA standard and contains all relevant information of a pediatric HIV patient. We extended the existing architecture of CDA consultation note in three dimensions: (1) HIV specific content, (2) HIV specific knowledgebase and (3) HIV specific presentation of content and knowledge. An example CDA consultation note is demonstrated following the proposed extension.
\end{abstract}

Keywords: HL7, clinical document architecture, CDA consultation note, pediatric HIV, knowledge integration.

\section{INTRODUCTION}

Human immunodeficiency virus (HIV) is one of the deadly viruses that affect the immune system in a human body. As a result, the immunity deteriorates and the affected person starts suffering from different opportunistic infections (OI), a deadly syndrome known as acquired immunodeficiency syndromes (AIDS). Although extensive research has been

\footnotetext{
${ }^{*}$ Corresponding Author: Debkumar Patra, Checktronix India Pvt. Ltd., New No. 9, Ramanathan Street, Kilpauk, Chennai - 600010, India. Email: debkumar.patra@gmail.com. Other authors: jay@cse.iitkgp. ernet.in, akmj@cse.iitkgp.ernet.in,bandana.majumdar@gmail.com, sangeetadb@yahoo.com,paul.soubhik@gmail.com.
} 
focused on HIV care and its prevention, modern medical science is still unable to bring the disease under control. During HIV treatment, doctors mostly depend on past evidences of patient care and its outcomes. A few AIDS control organizations such as $\mathrm{NACO}^{1}, \mathrm{WHO}^{2}$, $\mathrm{UNAIDS}^{3}$, etc. have published HIV care guidelines in multiple versions $[1,2,3,4,5]$ to inform HIV care providers of the current trends of treatment of the disease.

In electronic healthcare (ehealthcare), patient records are acquired and stored in electronic health record (EHR) located in EHR management systems (EHRMSs). EHR and EHRMS play vital roles in management of chronic disease such as HIV, where patient records are collected and assessed over a long treatment period.

EHRMSs developed by different vendors may not always be compatible to each other. Therefore, supporting standardized medical record interaction is one of the key requirements of an HIV EHRMS. Several medical standards are available in the market. We adopt only those standards provided by organizations recognized globally for medical standard development. Such organizations are Health Level 7 (HL7), Regenstrief Institute, Center for Disease Control and Prevention (CDC), etc. Accordingly, we have chosen Clinical Document Architecture (CDA) for clinical documentation, LOINC ${ }^{4}$ and $\mathrm{ICD}^{5}$ for naming and coding of clinical observations and diseases respectively.

CDA supports different types of clinical documents such as discharge summary, procedural note, consultation note, etc. Each of these document types serves a specific ehealthcare requirement. Discharge summaries are usually produced during patient discharge and it contains such information that would be used in next follow-up. Similarly, procedural note includes the details of non-operative procedures (while surgical or high risk procedures are managed in operative note). Though these document structures are derived from CDA, each document structure captures a particular set of patient records. Our intention is to compile all the patient records in a single standard document format. We have selected the architecture of CDA consultation note since it captures almost any type of patient records. Therefore, it is suitable for large scale study of HIV care ${ }^{6}$. Moreover, the architecture is designed in such a way that it can facilitate teleconsultation. This article focuses on teleconsultation. The following are the additional advantages that the selection of CDA consultation note brings forth as a standard of HIV patient record interaction:

- Extensibility: CDA consultation note is so flexible that it can be extended by adding new medical sections as required.

- Portability: In CDA consultation note, instead of storing data in database tables, patient records are kept usually in a single document. Therefore, it can be saved as a file and can be ported easily to some external disk or network.

\footnotetext{
${ }^{1}$ National AIDS Control Organization

${ }^{2}$ World Health Organization

${ }^{3}$ Joint United Nations Programme on HIV/AIDS

${ }^{4}$ Logical Observation Identifiers Names and Codes.

${ }^{5}$ International Classification of Diseases.

${ }^{6}$ Using CDA consultation note, HIV care centers would be able to upload patient records to national or regional HIV data repositories. Records collected thus can be analyzed and studied further for the up-to-date status of HIV infection and care.
} 
- Human Readability: A clinical document, by its property, has a human readable section in the body. This section may contain patient records in textual format which are to be rendered appropriately for human perception.

- Interoperability: Consultation documents conform to the standard of CDA consultation note. Therefore, CDA enabled EHRMSs may use consultation documents for seamless interaction among themselves.

Although the framework of CDA consultation note provides the above advantages, it does not address following needs.

Need for relevant knowledge: Relevant knowledgebase always helps a physician to analyze patient records and diagnose properly. Therefore, it is important to make relevant HIV knowledge available to a consultation note. According to the standard of CDA consultation note, a consultation document is entitled to capture a specific set of medical records and some meta information. However, CDA itself does not address the availability of medical knowledge in course of teleconsultation. HL7 has released a separate standard named 'Infobutton' [6,7] of late. The standard provides a generic system architecture for accessing context-aware medical information. It has an Infobutton manager system between the information source(s) and its requester. In our document based approach, implementing Infobutton might be heavy since document has limited processing capability with respect to an EHRMS. In this work, we keep the knowledge integration simple and specific to HIV care.

Need for appropriate presentation: CDA consultation note does not specify any conformance rule for presenting the document. Display of header and patient medical records is up to the preference of recipient of the document. Though records are often presented according to its structure, this is not user-friendly in every case. Many times it depends on nature of the data (quantitative or qualitative), significance of the data, etc. Apart from records, presentation of knowledge base is also important.

We have tried to address these requirements by integrating knowledge base and presentation directives in the consultation. To obtain the relevant knowledge and userfriendly presentation patterns, we have consulted a group of expert HIV physicians and followed the guidelines for HIV care and treatment in infants and children, provided by NACO [1]. In this article, we focus on construction of consultation note for pediatric HIV patients. In doing so, we have addressed four objectives such as: (a) capturing relevant patient records in the document, (b) presenting records in a user-friendly manner, (c) integrating appropriate knowledge base with records and (d) ensuring document confidentiality.

The paper is organized as follows: section 2 discusses relevant HL7 frameworks for ehealthcare interaction. In section 3, we discuss pediatric HIV and EHR-based requirements of pediatric HIV care. Section 4 elaborates our approaches to cope with these requirements. Section 5 presents a case study carried out on telemedicine where patient data exchange in standardized format is essential. Section 6 concludes the paper highlighting the future scopes of the work.

\section{DOCUMENT STANDARDS OF HL7}

The following are a few relevant HL7 document standards which are used as the base for HIV document construction. 


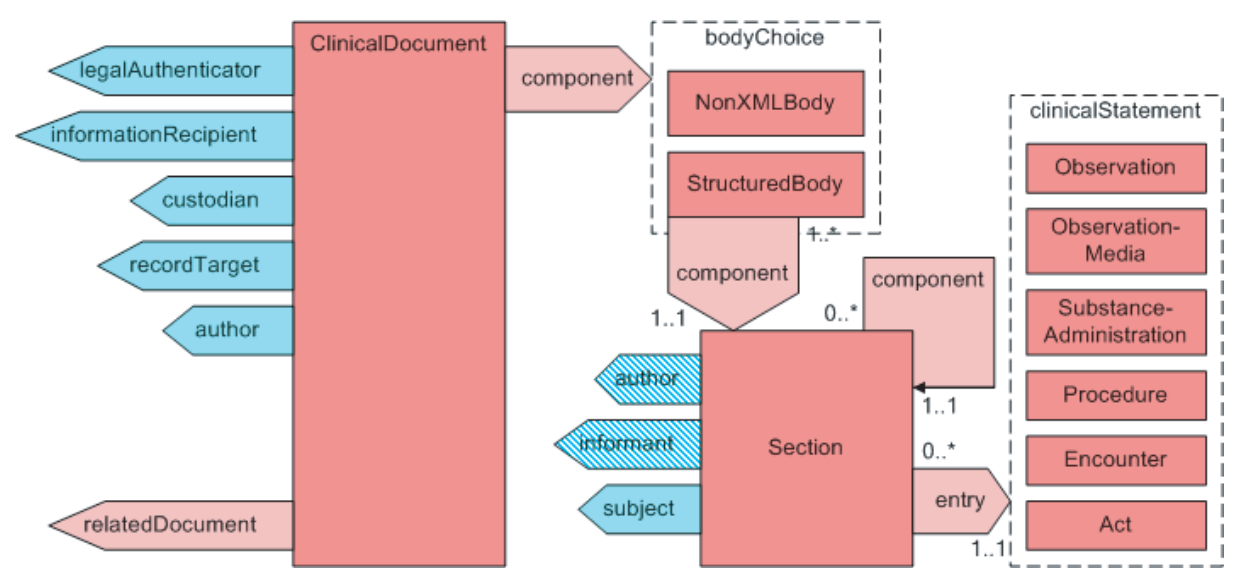

Figure 1. Partial schematic display of CDA Refined Message Information Model (RMIM) [8]. It is derived from HL7 Reference Information Model (RIM) [12]. RIM includes four types of classes viz. Act, Participation, Role and Entity which are represented conventionally in red, blue, yellow and green, respectively. In healthcare contexts, it is considered that an Act is performed by some Entities in specific Roles in certain Participation type. Color of each component in CDA RMIM indicates its base class type.

\subsection{Clinical Document Architecture (CDA)}

The CDA is an HL7 framework that specifies the structure and semantics of clinical documents for the purpose of exchange $[8,9,10,11]$. CDA document comprises two parts, viz. the header and the body. CDA header contains some meta information about the document such as document recipient, document version, authentication information, etc. On the other hand, CDA body consists of Sections ${ }^{7}$ which store patient medical records in classes such as Observation, Procedure, SubstanceAdministration, etc. (see Figure 1). A Section usually stores a set of related medical records such as liver function tests, lipid profile, etc. Since there is no limitation that the number of Sections a CDA document can incorporate, necessary Sections can be added in the document to capture HIV specific medical records.

\subsection{CDA Consultation Note}

CDA Consultation note is not a standard in true sense; rather, it is a specialization/restriction of CDA which fits in the EHR-based consultation scenario $[13,14,15]$. According to the framework, a consultation note imposes additional constraints over CDA header and body. It includes a few predefined Sections, viz. 'Reason for Referral', 'History of Present Illness', 'Assessment and Plan', etc., among which a few are mandatory (indicated by ' $R$ ') for document construction (see Table 1).

\footnotetext{
${ }^{7}$ These are sections in clinical document as medical sections.
} 
Table 1. Required (R) and optional (O) Sections of CDA Consultation Note as defined in 'HL7 Implementation Guide for CDA Release 2: Consult Notes, Release 1', a draft standard for trial use (DSTU).

\begin{tabular}{llll}
\hline Section Category & R/O & LOINC & Component Name \\
\hline Reason for Referral & $\mathrm{R}$ & $42349-1$ & REASON FOR REFERRAL \\
History of Present Illness & $\mathrm{R}$ & $10164-2$ & HISTORY OF PRESENT ILLNESS \\
Physical Examination & $\mathrm{R}$ & $29545-1$ & PHYSICAL FINDINGS \\
& $\mathrm{O}$ & Other Physical Examinations \\
Assessment and Plan & $\mathrm{R}$ & $51847-2$ & ASSESSMENT AND PLAN \\
& $\mathrm{R}$ & $51848-0$ & ASSESSMENT \\
& $\mathrm{R}$ & $18776-5$ & PLAN \\
Past Medical History & $\mathrm{O}$ & $11348-0$ & HISTORY OF PAST ILLNESS \\
Medications & $\mathrm{O}$ & $10160-0$ & HISTORY OF MEDICATION USE \\
Allergies & $\mathrm{O}$ & $48765-2$ & ALLERGIES, ADVERSE REACTIONS, \\
& & & ALERTS \\
Social History & $\mathrm{O}$ & $29762-2$ & SOCIAL HISTORY \\
Family History & $\mathrm{O}$ & $10157-6$ & HISTORY OF FAMILY MEMBER \\
& & & DISEASES \\
Review of Systems & $\mathrm{O}$ & $10187-3$ & REVIEW OF SYSTEMS \\
Diagnostic Findings & $\mathrm{O}$ & $30954-2$ & RELEVANT DIAGNOSTIC TESTS \\
Procedure History & $\mathrm{O}$ & $47519-4$ & PROCEDURE HISTORY \\
Immunizations & $\mathrm{O}$ & $11369-6$ & HISTORY OF IMMUNIZATIONS \\
Problems & $\mathrm{O}$ & $11450-4$ & PROBLEM LIST \\
Chief Complaints & $\mathrm{O}$ & $10154-3$ & CHIEF COMPLAINTS \\
\hline
\end{tabular}

\section{PEDIATRIC HIV AND HIV TREATMENT REQUIREMENTS}

We know that HIV affects the immune system which remains in primary stage for pediatric patients. Therefore, risk of failure of immune system in children is greater than that in adults, resulting in higher mortality rate in infected children. With proper treatment and care, children can be saved from being infected resultant rapid deterioration of health, or even death. To that notion, an EHRMS assists a physician providing appropriate medical information at appropriate time. Our approach of CDA consultation note facilitates interoperability among HIV EHRMSs.

Pediatric HIV patient care process is quite different from a general patient care process. Apart from the physical factors, treatment of HIV greatly depends on family history, life style, consciousness about the disease, etc. The following are a few treatment requirements for pediatric HIV care:

- In pediatric HIV care, family history, history of immunization, etc., are very crucial for appropriate clinical decisions. Therefore, a consultation document should include these records for the physicians.

\footnotetext{
8 ' $\mathrm{R}$ ' and ' $\mathrm{O}$ ' represent whether a CDA section is 'required' or 'optional' in HIV consultation document.
} 
- Knowledgebase support for patient data entry may reduce medical errors. Therefore, integration of knowledgebase in medical forms improves the quality of care.

- Proper visualization of records attracts doctor's attention. Different records provide different clinical impacts. Therefore, visualization is also an important factor for better treatment.

- Since HIV is a chronic disease, records collected in previous follow-ups influence its treatment plan. Visualizing these records associated with each visit helps a physician to understand the change in patient's condition over time.

- Patient record summary is a concise presentation of patient records. It displays important medical information collectively so that doctors can grasp the patient's overall health condition quickly.

In the following section, we discuss a few approaches that we have taken to address the above treatment requirements. We have introduced new components in the consultation document to capture HIV specific knowledgebase and presentation. In the definition of the document components, we have followed NACO's HIV care recommendations [1].

\section{NEW APPROACHES}

This section discusses on the proposed approaches to fulfill the objectives we pointed out in the introduction.

\subsection{Integration of Essential Data Set for HIV Care and Monitoring of Patients under Anti-Retroviral Therapy ${ }^{9}$ (ART)}

HIV care guidelines [2, 3] have specified a minimum set of HIV records which are essential for standard HIV care and ART patient monitoring. As recommended, these records are classified in four categories: (1) demographic information, (2) HIV care and family status, (3) ART summary and (4) patient encounter information. However, except the first category, others essentially include patient health records. We have classified these health records in a few sections as listed in Table 2. Being a pediatric HIV consultation document, it integrates a few HIV specific sections which are not usually included in a consultation document. Therefore, our objective is to store demographic information and medical information in a clinical document following the document standards. The following two subsections describe how patient demographics and patient medical records are captured in a CDA consultation note.

\subsubsection{Demographic Information}

According to the guidelines [2,3], patient demographics include patient's name, sex, date of birth, marital status, unique ID number, contact information, etc. In a clinical document, demographic information is stored in element 'recordTarget' (XPath: /Clinical Document/recordTarget) - the patient. In 'recordTarget' an element 'patient' (/Clinical Document/recordTarget/- patientRole/patient) stores all these demographic information.

\footnotetext{
${ }^{9}$ Anti-retroviral therapy is an important part of HIV treatment. It consists of regimens of anti-retroviral drugs to maximally stop the progression of HIV disease [16].
} 
For pediatric patients, guardians play an important role. Therefore, guardian information is mandatory and is included in the consultation note. In 'patient', there is a child element named 'guardian' that stores guardian information. A snippet of document presenting demographics is listed in Appendix A.

\subsubsection{Health Information}

In a clinical document, medical records are stored in the body of the document. Structured body of a CDA document comprises a set of components. Each component has a Section which stores the medical information. A Section can be either atomic (e.g., immunization) or composition of other components (e.g., physical examination). The Section-component relation is recursive and might be executed indefinitely. We map these medical record sections to the Sections in the consultation document; i.e., all the records of a medical section are stored in a section of a consultation note and that section is identified by appropriate LOINC code. In a CDA section, records are presented in narrative format (in element XPath: /ClinicalDocument/.../section/text). In level 3 clinical documents, beside narrative display, patient records are stored in coded format (in element XPath: /ClinicalDocument/.../section/entry). We are currently populating records in narrative format because all the patient data in our database are not structured to be compatible with HL7 standard.

According to the guidelines, some medical records are essential for clinical evaluation. We have marked these records in the Section and component levels (indicated by ' $R$ '). When information for a required Section is unavailable, 'Blank'/'Not Recorded' is set in the narrative block to represent unavailability. An instance of medical record incorporation in consultation document is listed in Appendix B.

Comparison of Table 1 and Table 2 shows that all the required Sections in the former are included in the latter, indicating that customization of CDA consultation note in pediatric HIV realm does not violate the standard in terms of records included in the document.

\subsection{Confidentiality of Document}

The impact of HIV/AIDS on family and society is tremendous and multi-faceted. Ignorance of HIV infection stems from prejudice in human mind. Exposure of HIV information and its undesired interpretation influence adversely both the patient and others. It is important to maintain the confidentiality of HIV records and identity of the patient to whom the records belong. We have configured/populated following document elements properly to enhance confidentiality: (a) XPath: /ClinicalDocument/ ConfidentialityCode specifies the confidentiality assigned to a consultation note. We set confidentiality of HIV consultation document to 'HIV' (codeSystem: 2.16.840.1.113883.5.25), indicating that the document contains HIV related information. (b) XPath: /ClinicalDocument/informationRecipient specifies the person or the organization that is going to receive the document in order to enhance confidentiality of the document. 
Table 2. List of required (R) and optional (O) Sections of HIV records.

\begin{tabular}{llll}
\hline Section Category & R/O & LOINC & Component Name \\
\hline Reason for Referral & $\mathrm{R}$ & $42349-1$ & REASON FOR REFERRAL \\
Chief Complaints & $\mathrm{R}$ & $10154-3$ & CHIEF COMPLAINTS \\
History of Present Illness & $\mathrm{R}$ & $10164-2$ & HISTORY OF PRESENT ILLNESS \\
Past Medical History & $\mathrm{R}$ & $45683-0$ & HISTORY OF HIV EXPOSER \\
& $\mathrm{R}$ & $45683-0$ & OPPORTUNISTIC INFECTIONS \\
& $\mathrm{R}$ & $45688-9$ & TUBERCULOSIS HISTORY \\
& $\mathrm{R}$ & $48765-2$ & ALLERGIES, ADVERSE \\
& & & REACTIONS, ALERTS \\
R & & $10160-0$ & HISTORY OF MEDICATION USE \\
Birth History & $\mathrm{O}$ & Other Past Medical History \\
Immunizations & $\mathrm{O}$ & $57130-7$ & BIRTH HISTORY, PMTCT \\
Social History & $\mathrm{O}$ & $11334-0$ & DEVELOPMENT MILESTONES \\
& $\mathrm{R}$ & $11369-6$ & HISTORY OF IMMUNIZATIONS \\
& $\mathrm{R}$ & $10157-6$ & HISTORY OF FAMILY MEMBER \\
Review of Systems & $\mathrm{O}$ & $29762-2$ & SOCIAL HISTORY \\
Physical Examination & $\mathrm{O}$ & $28522-1$ & SOCIAL STATUS \\
& $\mathrm{O}$ & $28420-8$ & INCOME STATUS \\
& $\mathrm{R}$ & $10187-3$ & REVIEW OF SYSTEMS \\
& $\mathrm{R}$ & $29545-1$ & PHYSICAL FINDINGS \\
Diagnostic Findings & $\mathrm{R}$ & $11340-0$ & GROWTH RECORD \\
& $\mathrm{O}$ & Other Physical Examinations \\
& $\mathrm{O}$ & $45182-3$ & GENOTYPE \\
& $\mathrm{R}$ & $17146-2$ & CD4-CD8 COUNT \\
Assessment and Plan & $\mathrm{O}$ & $24369-2$ & HEMATOLOGY \\
& $\mathrm{O}$ & Other Diagnostic & Findings \\
& $\mathrm{R}$ & $51848-0$ & ASSESSMENT \\
& $\mathrm{R}$ & $29548-5$ & DIAGNOSIS \\
& $\mathrm{R}$ & $34865-6$ & COUNSELING \\
& $\mathrm{O}$ & $11450-4$ & PROBLEM LIST \\
& $\mathrm{R}$ & $18776-5$ & PLAN \\
& $\mathrm{R}$ & $4421-4$ & TB MEDICINES \\
$\mathrm{R}$ & $4081-6$ & CTX PROPHYLAXIS \\
& $\mathrm{R}$ & $45260-7$ & ANTIRETROVIRAL THERAPY \\
& $\mathrm{O}$ & $47519-4$ & PROCEDURE HISTORY \\
\hline \multirow{5}{*}{ Medications } & & &
\end{tabular}

\subsection{Association of Knowledgebase}

Apart from medical records, NACO's patient care guidelines also provide different HIV-specific knowledge bases. Basically, these knowledge bases are for two types of knowledge: 
Table 3. Partial list of available knowledge base defined in the NACO guidelines

\begin{tabular}{|c|c|c|}
\hline Section & Knowledgebase & Type \\
\hline \multirow[t]{5}{*}{ ASSESSMENT } & Decision-making regarding switching to second line therapy & Information \\
\hline & Primary opportunistic infection (OI) prophylaxis in children & Information \\
\hline & Using the WHO Pediatric Clinical Staging System & Information \\
\hline & When to start ART & Information \\
\hline & Who should receive cotrimoxazole prophylaxis & Information \\
\hline \multirow[t]{7}{*}{ DIAGNOSIS } & Clinical diagnosis and management of common $\mathrm{OI}$ & Information \\
\hline & $\begin{array}{l}\text { Differentiating immune reconstitution inflammatory } \\
\text { syndromes (IRIS) and antiretroviral (ARV) drugs' } \\
\text { side effects }\end{array}$ & Information \\
\hline & Presumptive and Definitive Criteria & Information \\
\hline & WHO Clinical Staging & Information \\
\hline & HIV diagnosis in children younger than 18 months with & Algorithm \\
\hline & DNA-polymerase chain reaction (PCR) & \\
\hline & HIV diagnosis in children older than 18 months & Algorithm \\
\hline
\end{tabular}

1. knowledge of static information, e.g., HIV staging for pediatric patients with confirmed HIV infection,

2. knowledge of methods and algorithms, e.g., algorithm for diagnosis of HIV in children older than 18 months.

A few such knowledgebases along with their types are listed in Table 3. In knowledge base integration, our objectives are (1) to gather relevant knowledge, and (2) to present that knowledge appropriately as elaborated in the following subsections.

\subsubsection{Collection and Mapping of Knowledge}

Collection of HIV knowledge and its mapping to a class of health records are mainly performed based on guidelines of NACO. We have also consulted expert HIV physicians for this purpose. As per their recommendations, available knowledge bases are categorized in the following eight major groups: Child immunization, Laboratory examination, Physical examination, Assessment, Diagnosis, Medication of tuberculosis, Cotrimoxazole prophylaxis, and Antiretroviral therapy (ART).

We have mapped these knowledge groups to an appropriate CDA Section discussed in subsection 4.1. This knowledge-record mapping helps a doctor to view relevant knowledge in the context of record. Figure 2 depicts the mapping between knowledge base and CDA Section along with other mapping relations.

\subsubsection{Presentation of Knowledge}

Appropriate presentation of knowledge is important to express its inherent information most effectively. HIV care guidelines did not address the issue of presentation of 


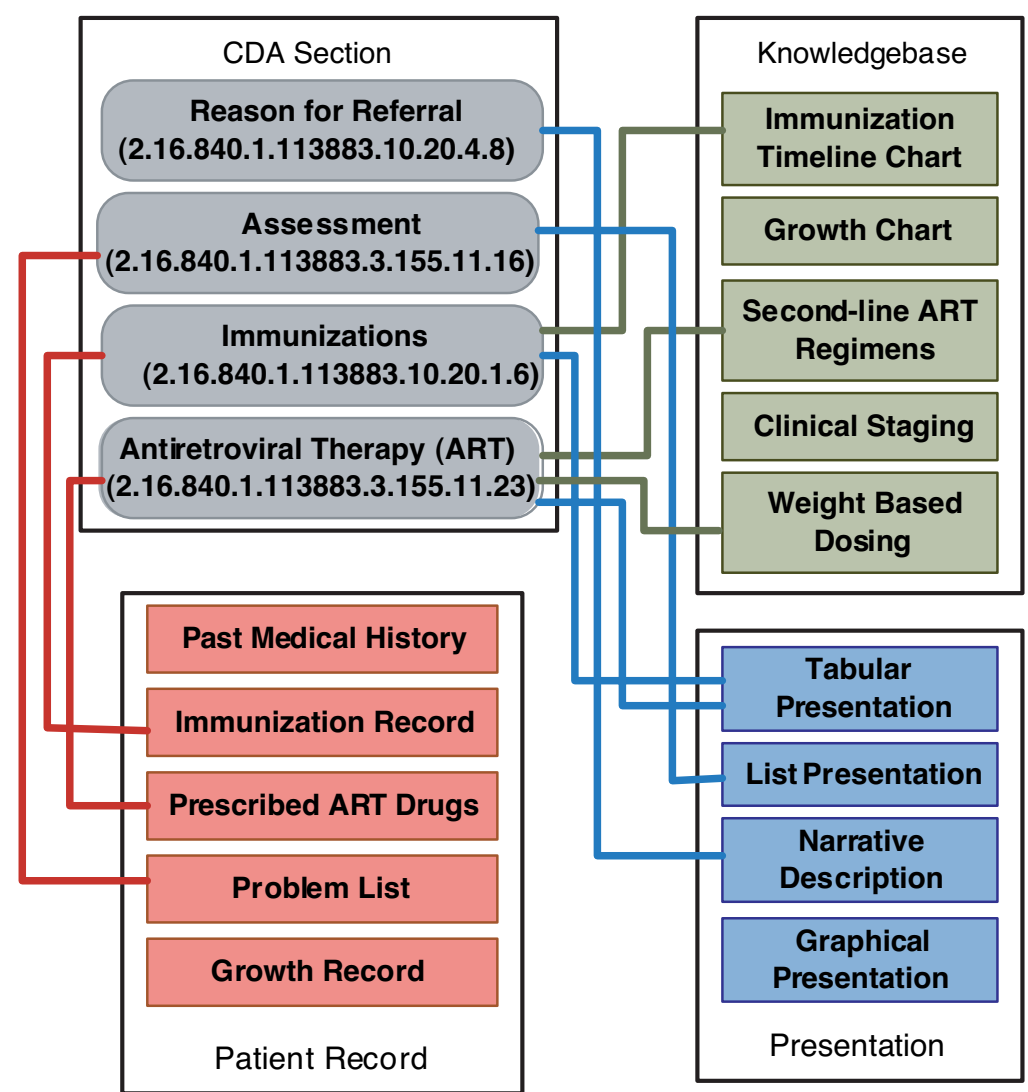

Figure 2. Schematic display of mapping among medical Section, patient record, knowledge base, and presentation. The numbers in parentheses are essentially object identifiers (refer to http://www.oid-info.com, http://www.hl7.org/oid) which uniquely identify Section templates.

knowledge. We have identified a few patterns for knowledge presentation after discussing with HIV physicians.

- Textual presentation: It is further classified into (1) tabular presentation, (2) list presentation, (3) paragraph presentation, etc. In each format, additional text formatting can be applied to highlight important part of the text.

- Graphical/pictorial presentation: It can also be further classified into (1) graph plots (suitable for quantitative information), (2) presentation with appropriate legends (suitable for qualitative information), (3) displaying as image, etc.

To facilitate the process of presentation, we have used HTML since it supports a wide variety of presentation including those mentioned above. As an example, Figure 3 


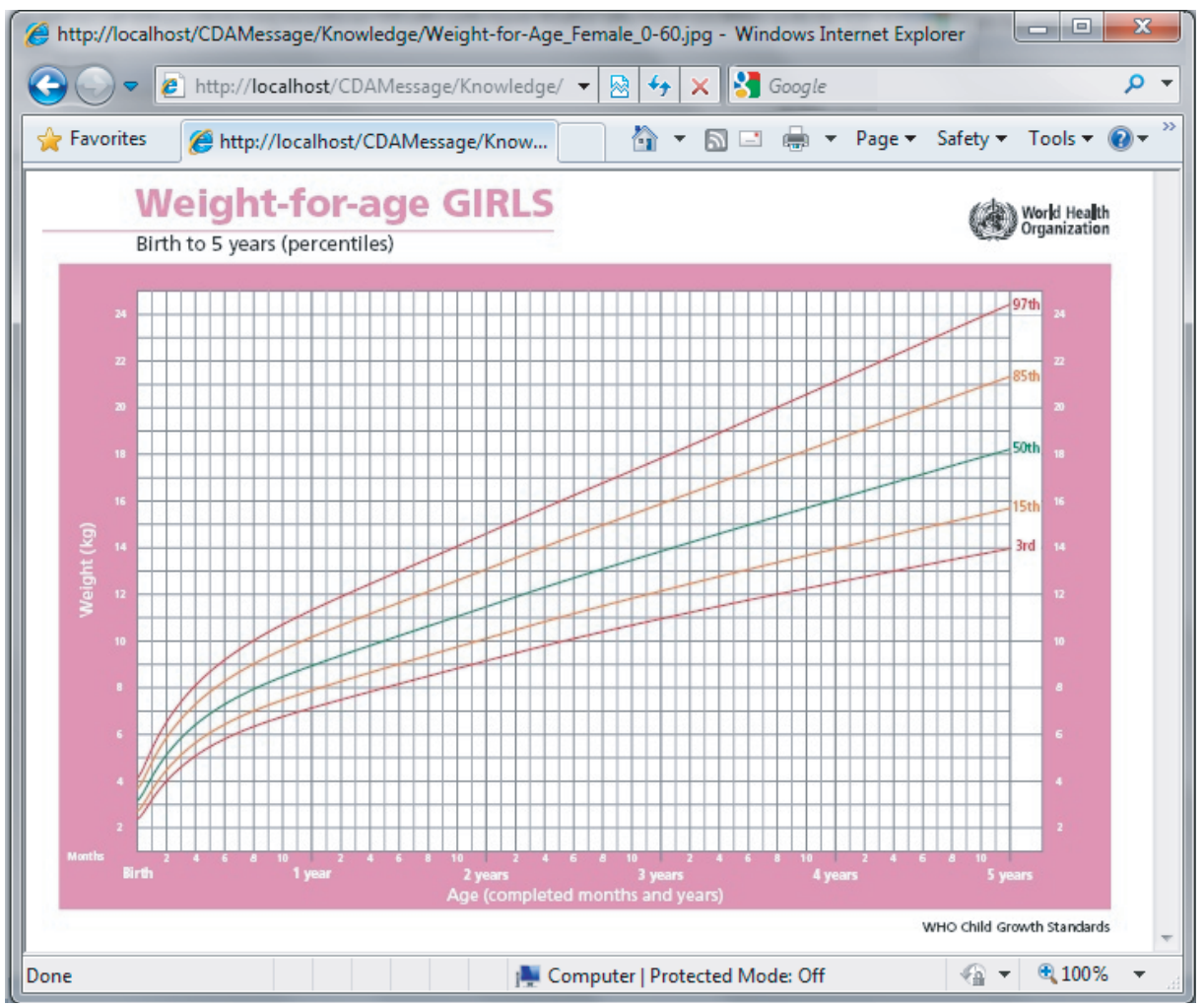

Figure 3. Weight-for-age percentiles for girls, birth to 5 years old

shows, the weight-for-age percentiles for girls from birth to five years of age. $50^{\text {th }}$ reference curve, as shown in the chart, represents that $50 \%$ of the reference girls (aged between 0 to 5 years) have at least that much weight that the curve shows. Thus, the growth chart helps a doctor to find out a child's growth in reference to other children. For algorithmic knowledge base, we have displayed flow-charts or formula as image. Since a consultation document is not an application, execution of algorithm in real environment is limited for the document.

\subsubsection{Integration of Knowledge}

To achieve better outcome, it is essential to visualize the appropriate knowledgebase with medical records. Embedding knowledge base in each document is not a good choice since it increases document size. Increase in size requires more storage space and bandwidth during exchange through network. Therefore, we kept these knowledgebases in the public domain (e.g. WWW) and link these through URL references (refer to Appendix C). Linking is advantageous in four respects: (1) replication of knowledgebase in every document is avoided; (2) knowledge information 
can be accessed on demand; (3) updating process is easy and every document gets its reflection (when knowledge is stored in a central repository); (4) through dynamic linking most recent knowledge can be accessed (when there are multiple knowledge repositories at different locations).

\subsection{Presentation of Document Content}

Not only for knowledgebase, user-friendly presentation is also required for medical records. In the last subsection, we covered a few typical patterns of knowledge presentation which we implemented in HTML. As discussed earlier, a CDA document supports structure for storing medical records in narrative (human-readable) and coded format (machine-readable). Our concern is the presentation of records readable to human. A small set of presentation directives (similar to HTML) are allowed within the narrative block (XPath: /ClinicalDocument/.../text) for section level formatting of records. In addition, the document is finally presented as an HTML document using XSLT translation and appropriate style sheets. Specific presentation templates have been applied for each CDA Sections. A snippet of such section-based presentation is listed in Appendix D.

As per recommendations in draft standard of consultation note, a couple of header information must be displayed during document rendering. Examples of such information are listed below:

- Document title and date,

- Service and encounter types, and date ranges as appropriate,

- All persons named along with their roles, participations, participation date ranges, identifiers, addresses, and telecommunications information,

- $\quad$ Selected organizations named along with their roles, participations, participation date ranges, identifiers, addresses, and telecommunications information,

- $\quad$ Date of birth for record target (patient).

These recommendations are quite general and do not address HIV specific requirements. We have adopted the following visualization patterns to present HIV records in a more user-friendly manner.

- $\quad$ Pediatric growth information (weight, height, head circumference with respect to age) are visualized graphically through $2 \mathrm{D}$ curves.

- History of affected family members is rendered as a family hierarchy where each node represents a family member. A node is presented with a set of graphical legends which signify important HIV information of a family member.

- Chronological display of results in physical and laboratory examination such as CD4 count, viral load, etc.

\section{CASE STUDY: TELEMEDICINE}

Telemedicine is an electronic healthcare process which involves telecommunication and information technologies to provide healthcare services and information from distant locations. One such telemedicine process is teleconsultation where a patient is 
referred and treated by remote care provider(s). During the patient referral, medical records are sent to the referred doctor ${ }^{10}$ who analyzes these records and provides opinions/comments as another set of records. In this section, we discuss the use of CDA consultation note in pediatric HIV teleconsultation. In the EHRMS based teleconsultation scenario, it is often essential to produce clinical documents/messages from one EHRMS and consume at other. In this work, a prototype subsystem has been implemented that exports/imports clinical documents dynamically from/to iMedikD [17] (an EHRMS developed at IIT Kharagpur). The subsystem comprises two modules, viz. export and import module.

Let us consider a fictitious pediatric HIV patient case (id:BCRH2506090000) from iMedikD. The patient has been tele-referred accordingly, with consultation document prepared. A few portions of this document are shown in the appendices. In the following subsections, we discuss the referral procedure in reference to this document.

\subsection{Patient Referral Workflow using Clinical Document}

Depending on the disease type, the export module constructs a consultation document before it is exported. The module basically fetches patient's medical records from the database and structures them in XML format in compliance with clinical document architecture. This document is transferred to the referred doctor. One such document is shown in Appendix E. Along with the consultation document, a few auxiliary documents such as XML style sheet (XSLT), Java scripts are sent for the display of clinical document and further data insertion (referred doctor's opinions/comments). These documents are almost static and are not created in every patient referral. A referring doctor selects an appropriate XSLT document that displays a form with necessary fields to present query(ies). Besides, the doctor can also specify his/her query(ies) in the reason for referral section of the document.

At the referred doctor's end, a browser that supports XML rendering through XSLT and Java script (e.g. Firefox, Internet Explorer) can be used for the referral operations. Beside the display of patient records, a form is viewed in the document using XSLT. Different input fields (mostly related to assessment and medication) in the form enable the referring doctor to input details of the query. Appendix E displays the consultation document where such a form is embedded. After submission of the form, Java scripts save the referred doctor's input in another CDA document in the local system (assuming the document is trusted). Such document is appended to the original CDA document, and sent back to the referring system/doctor (iMedikD in present case). Import module imports this document and populates the database with additional information. This workflow is depicted in Figure 4. A detail account of importing and exporting document is described in the following subsections.

\footnotetext{
${ }^{10}$ Sharing a document raises the issue of ownership. However, this needs to be addressed by the users, by establishing the norms and protocols regarding this matter. The system assumes that with mutual agreement, consultation notes are shared.
} 


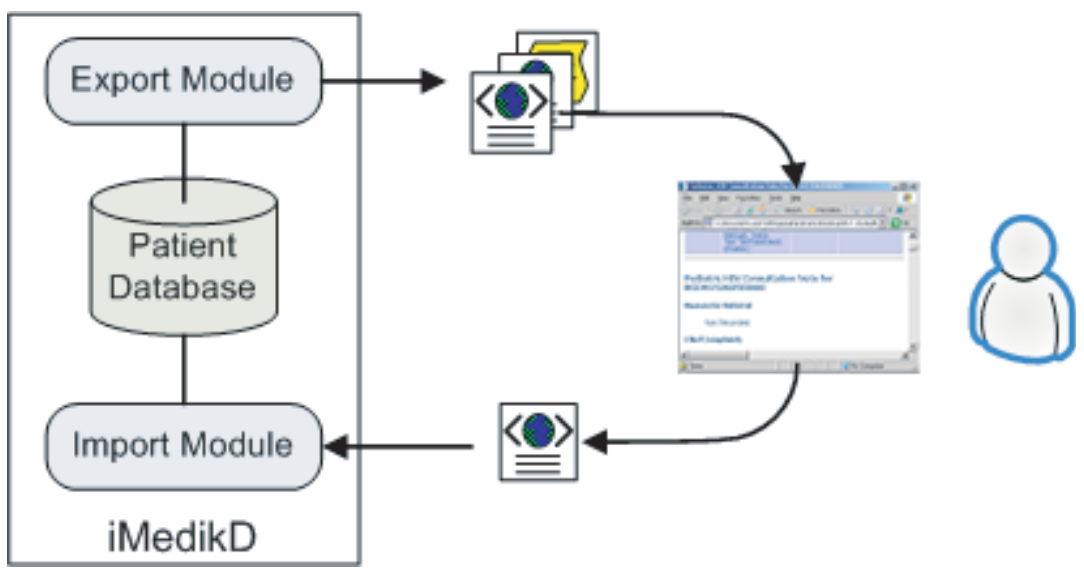

Figure 4. Workflow of referral process using a clinical document

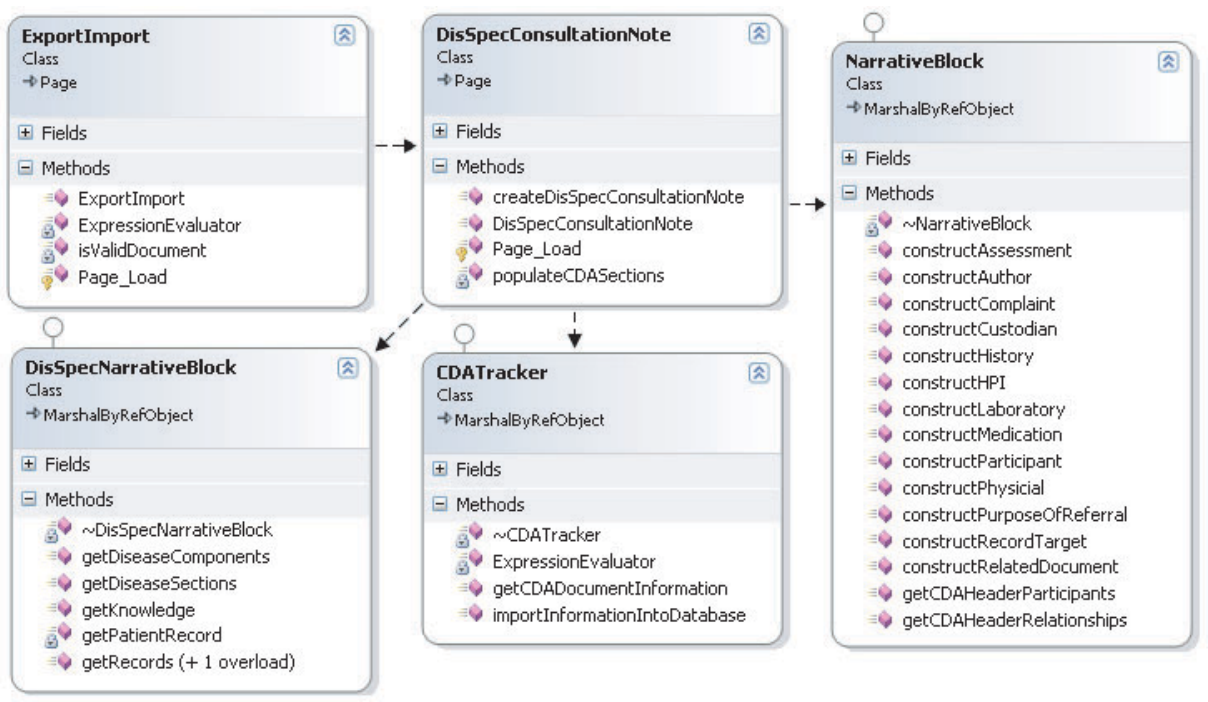

Figure 5. $\mathrm{UML}^{11}$ class diagram for generation of clinical document

\subsection{Generation of Clinical Document from EHRMS}

Document generation process includes construction of CDA header and CDA body. In order to construct CDA header, a pediatric HIV specific template was designed which includes a few essential attributes and elements such as 'recordTarget', 'custodian', 'author', 'relatedDocument', 'participants' etc. Content of each element in the template is

${ }^{11}$ Unified Modeling Language; an abstract modeling language for software development. 


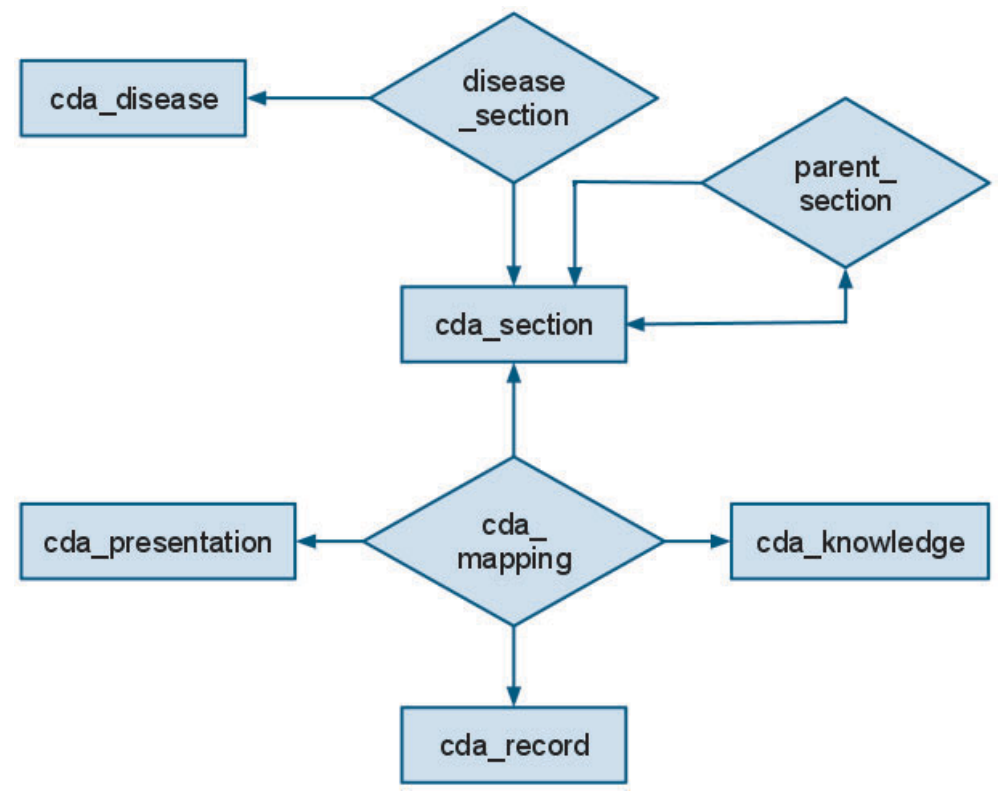

Figure 6. Entity relationship diagram for knowledge, record and presentation mapping to Sections.

retrieved from the patient database in consultation with a mapping table. The mapping table basically stores mapping relations between XPath of a CDA header element and database location where corresponding data exist. Appendix A shows the 'recordTarget' header element of a clinical document mentioned previously. It carries different demographic information and the guardian information of a patient whom the document belongs to.

The body of a CDA document is also constructed in a similar manner. CDA body comprises a series of medical sections with some of which mandatory. There is a set of tables mapping different pediatric HIV records, relevant knowledge bases and presentation patterns to appropriate medical Sections (refer to Figure 2). Figures 5 and 6 present the class dependency and relationship of aforementioned entities, respectively. In Appendix B, we display the medication section of the document including $T B$ medication, antiretroviral medication etc. The document also contains other sections which are not displayed here for shortage of space. Appendix C presents the knowledgebase integration with a section named immunization. This section contains patient's records of immunization and a hyperlink to the immunization knowledgebase. In Appendix D, a portion of the XSL style sheet is shown where presentation patterns are defined for two sections: reason for referral and chief complaint. According to the style sheet records of reason for referral are rendered in paragraphs. Finally, Appendix E displays a portion of the document as it is rendered in internet explorer. The document displays the patient records, query form and links to knowledge bases. 


\subsection{Importing Clinical Document to EHRMS}

Since CDA document is a well defined XML document, header and section contents are retrieved using XPath expressions. Like the document generation, mapping tables are also used to map the data in a document section to appropriate database tables. Moreover, in this scenario, a referred doctor does not need to import patient records to the local EHRMS. Every operation at the referred end such as visualization, entry of opinion, etc. is carried out according to working principle defined by the exporting EHRMS. Therefore, document generated at the referred end is always recognized by the exporting EHRMS. However, when the document contains unrecognized data, it is stored in the database for manual analysis.

\section{CONCLUSION}

In this work, we have presented an architecture of standardized consultation document for a chronic disease named 'pediatric HIV'. Including medical records, we have presented a few approaches for integrating HIV specific knowledgebase and their appropriate presentation. We have also shown a mechanism for expressing queries (raised by referring doctors) during document display. The following scopes are to be addressed in future works:

- Clinical document constructed in the present work is of level 2. Patient records can be coded in the entry element (XPath:/ClinicalDocument/component/ structuredBody/component/section/entry) to upgrade the document into level 3.

- In the present work, the medical records are mainly presented in tabular format and knowledgebase is displayed with those records side-by-side. This can be improved by integrating knowledgebase with records in a more user-friendly manner.

- $\quad$ Display of record for each visit and summarization of medical records (discussed in section 3) can be implemented using proper indexing within the document.

\section{ACKNOWLEDGMENT}

This work was conducted under a sponsored project supported by the Ministry of Communication and Information Technology, Government of India (refer Grant no. 1(23)/2006-ME\&TMD, Dt. 07/03/2007).

\section{REFERENCES}

[1] Indian Academy of Pediatrics, National AIDS Control Organization (NACO), Guideline for HIV care \& treatment in infants \& children, August, 2007, Source: http://www.nacoonline.org/upload/ Publication/Treatment Care and support/Guidelines for HIV care and treatment in Infants and children.pdf, Accessed On: June, 2010.

[2] WHO, UNAIDS, USAID, CDC, HRSA, GFATM, Interim Patient Monitoring Guidelines for HIV Care and ART (Based on the WHO Patient ART Monitoring Meeting). Geneva, 29-31 March 2004, Source: http://www.who.int/3by5/publications/en/patientguidelines2.pdf, Accessed On: June, 2010.

[3] WHO, UNAIDS, USAID, Patient monitoring guidelines for HIV care and antiretroviral therapy (ART). 2006, Source:http://www.who.int/3by5/capacity/ptmonguidelinesfinalv1.pdf, Accessed On: June, 2010.

[4] Paul S, DasBhattacharya S, Patra D, Majumdar AK, Mukhopadhyay J, Majumdar B, Sudar A, A WebBased Electronic Health Care System for the Treatment of Pediatric HIV. International Conference on e-Health Networking, Applications \& Services (HEALTHCOM 2009), 16-18 December, 2009, Page(s):175-180, Sydney, Australia. 
[5] DasBhattacharya S, Paul S, Raj R, Patra D, Mukhopadhyay J, Majumdar B, Bhattacharyya S, Majumdar AK, I-Medik a Smart Mobile EHR Designed to Improve the Quality of Care Delivered to Children with HIV in India. mHealth Summit, 29-30 October, 2009. Washington DC, USA.

[6] Jenders R, Greenes R, Sailors RM, Infobutton Communication Standard. Source:http://groups. medbiq.org/medbiq/download/attachments/229554/DSTU-ballot-documentation-infobutton-2-2206.doc? version=1\&modificationDate=1179521456000, Accessed On: June, 2010.

[7] Fiol GD, Rocha R, Cimino JJ, HL7 Infobutton Standard API Proposal. Source:http://www. h17.org/Library/Committees/dss/HL7-Infobutton-API-v2.2-20040224.doc, Accessed On: June, 2010.

[8] Dolin RH, Alschuler L, Boyer S, Beebe C, Behlen FM, Biron PV, Shvo AS, Model Formulation: HL7 Clinical Document Architecture, Release 2. The Journal of the American Medical Informatics Association (JAMIA), 2006, Volume 13, Page(s): 30-39.

[9] Health Level Seven, Inc., Implementation Guide for CDA Release 2 - Level 1 and 2 - Care Record Summary (US realm). June, 2006.

[10] Alschuler Associates LLC. Quick Start Guide HL7 Implementation Guide: For Simple CDA Release 2 Documents, Version 1.5. The Journal of the American Medical Informatics Association (JAMIA), November 15, 2007, Source:http://www.alschulerassociates.com/library/documents/cda_qsg_ v1.5.zip, Accessed On: June, 2010.

[11] Ferranti JM, Musser RC, Kawamoto K, Hammond WE, The Clinical Document Architecture and the Continuity of Care Record: A Critical Analysis. Journal of the American Medical Informatics Association, May/Jun 2006, Volume 13, No. 3, Page(s):245-252.

[12] Health Level Seven, Inc., HL7 Reference Information Model (RIM) version 2.19, November 2007, Source: http://www.hl7.org/documentcenter/public/standards/V3/RIM/C30219/rim0219c.zip, Accessed On: June, 2008.

[13] Health Level Seven, Inc., HL7 Implementation Guide for CDA Release 2: Consultation Notes (U.S. Realm), Draft Standard for Trial Use Release 1, Level 1, 2 and 3. July, 2008.

[14] Health Level Seven, Inc., HL7 Implementation Guide for CDA Release 2: History and Physical (H\&P) Notes, Release 1, Draft Standard for Trial Use. August, 2008.

[15] British Columbia, Vancouver Island Health Authority, e-MS Clinical Document Architecture Implementation Guide. January 2006, Source: http://xml.coverpages.org/eMS-CDA-Draft20040922.pdf, Accessed On: June, 2010.

[16] World Health Organization (WHO), Antiretroviral Therapy. Source: http://www.who.int/hiv/topics/ treatment, Accessed on: April, 2011.

[17] Patra D, Ray S, Mukhopadhyay J, Majumdar B, Majumdar AK, Achieving e-Health Care in a Distributed EHR System. International Conference on e-Health Networking, Application \& Services (HEALTHCOM 2009), 16-18 December, 2009, Page(s):175-180, Sydney, Australia. 


\section{APPENDICES}

\section{A. INCORPORATING DEMOGRAPHIC INFORMATION IN THE DOCUMENT}

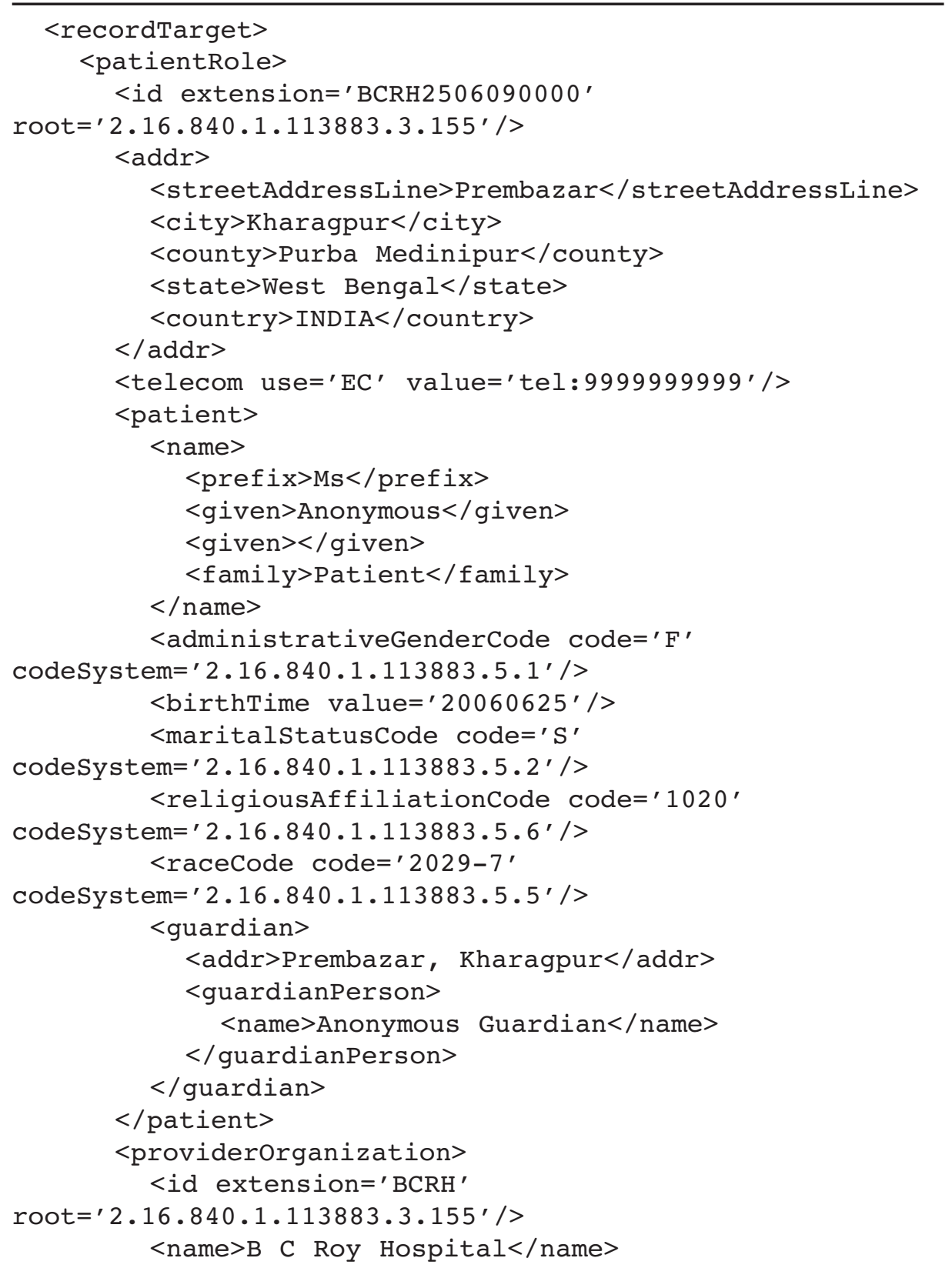




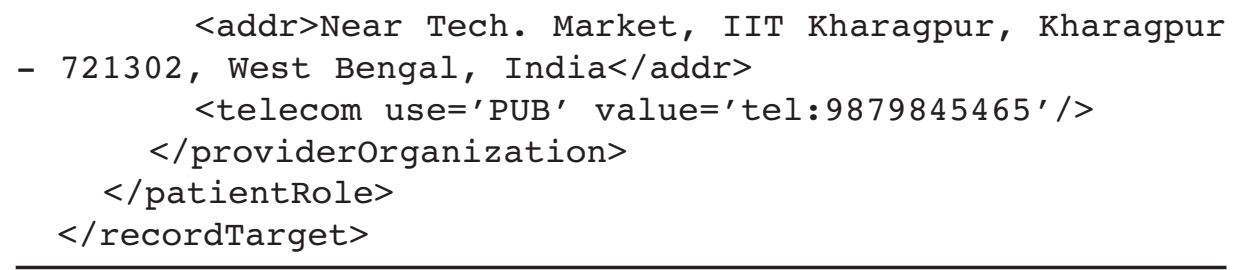

\section{B. INCORPORATING MEDICATION INFORMATION INTO THE DOCUMENT}

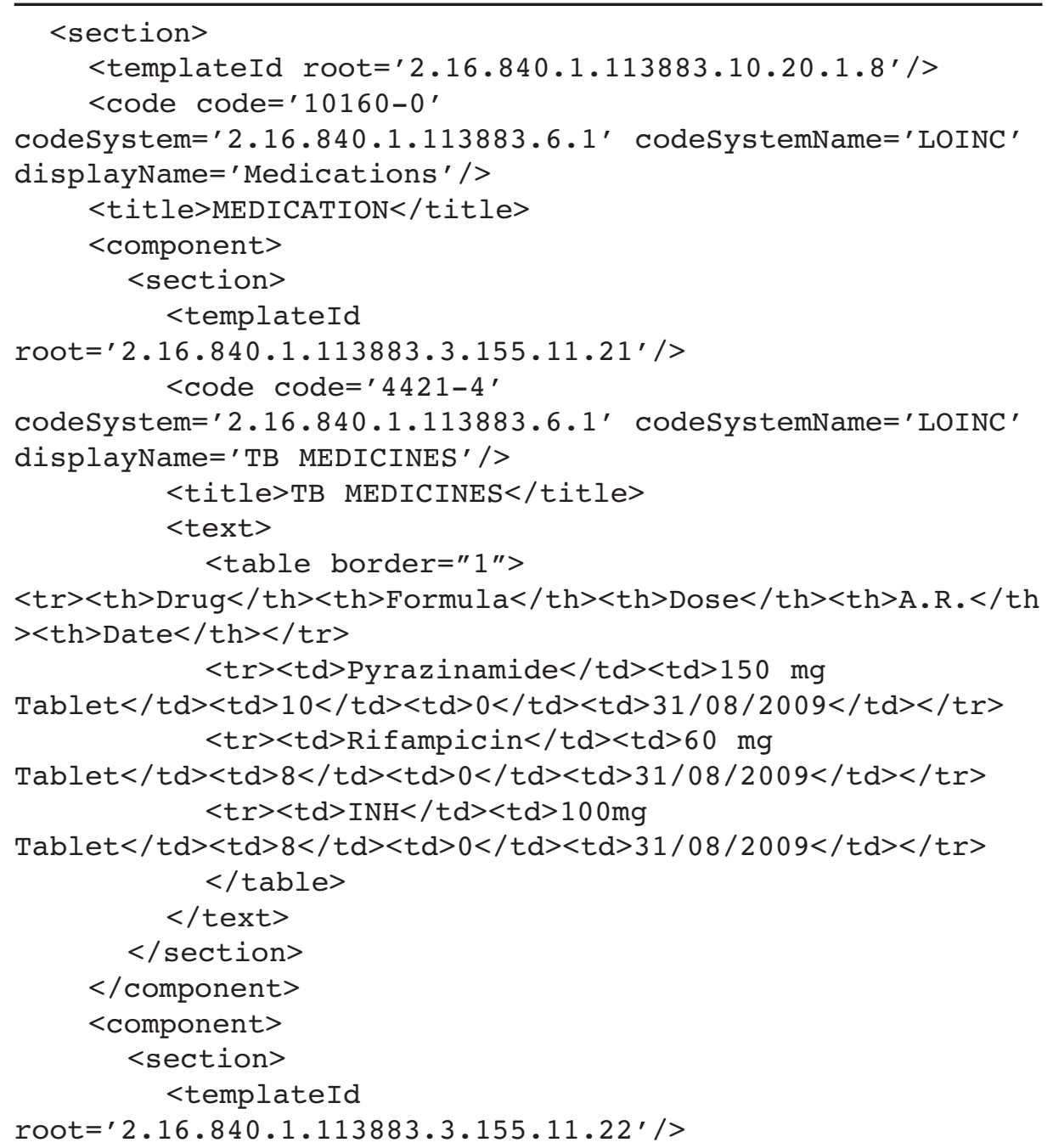




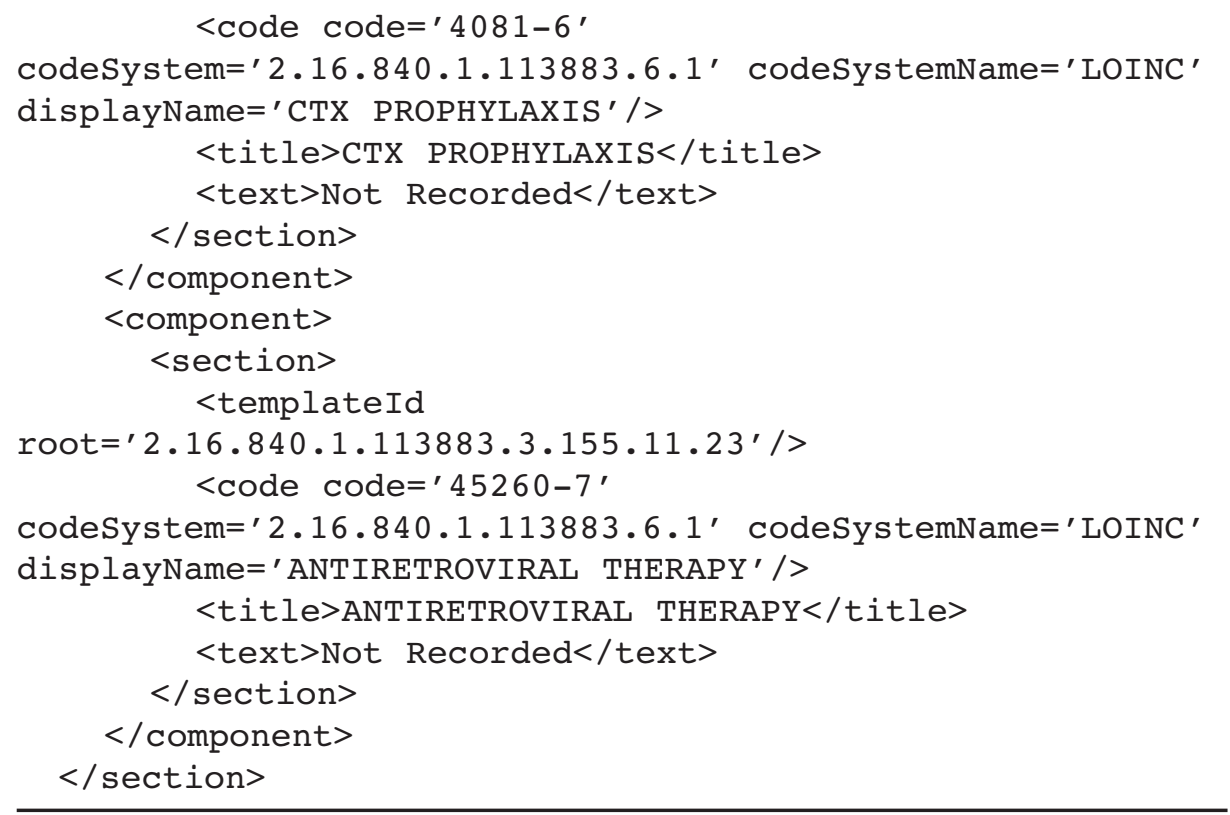

\section{INCORPORATING KNOWLEDGE BASES IN THE DOCUMENT}

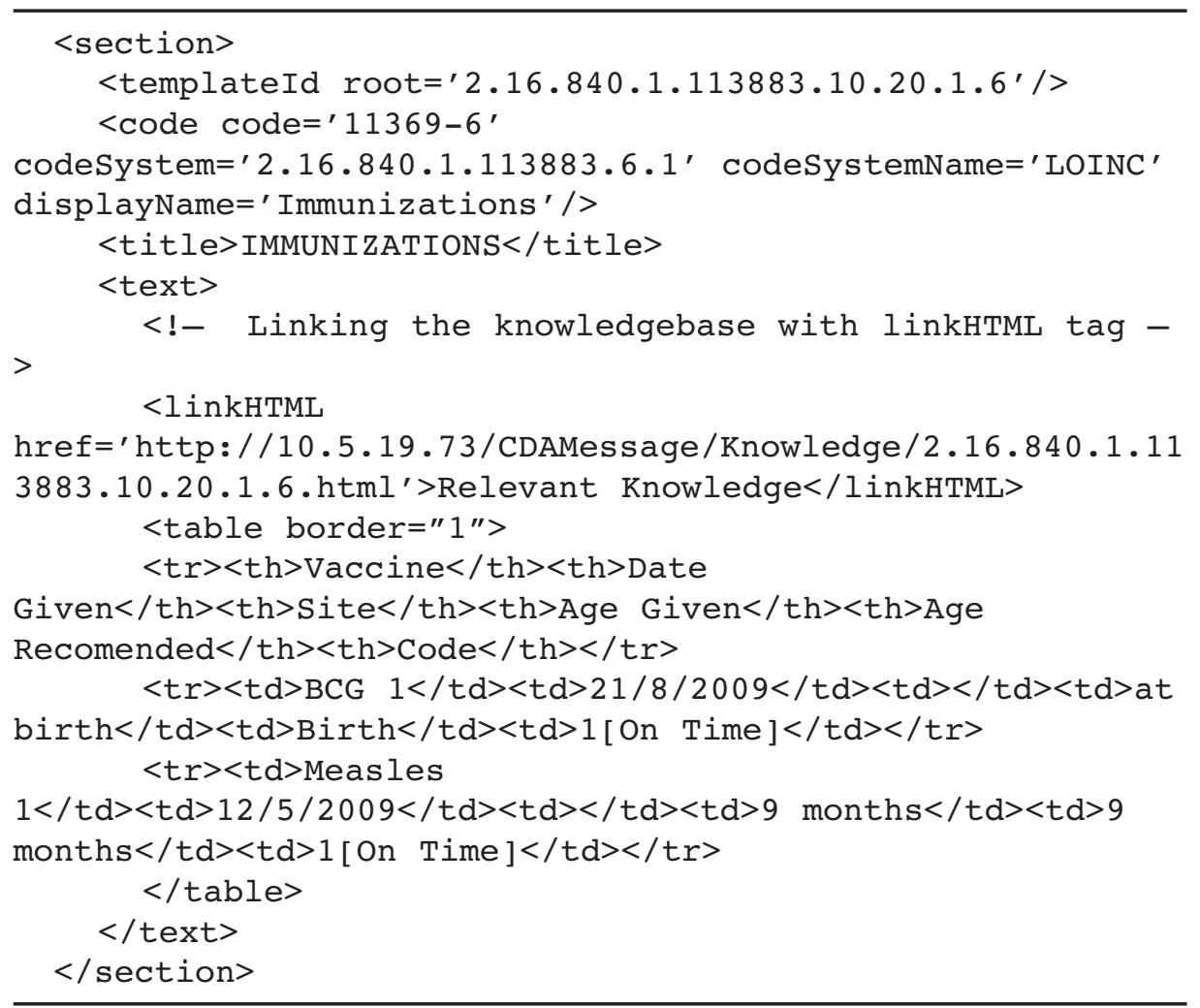




\section{SECTION SPECIFIC PRESENTATION USING XSL STYLE DIRECTIVES}

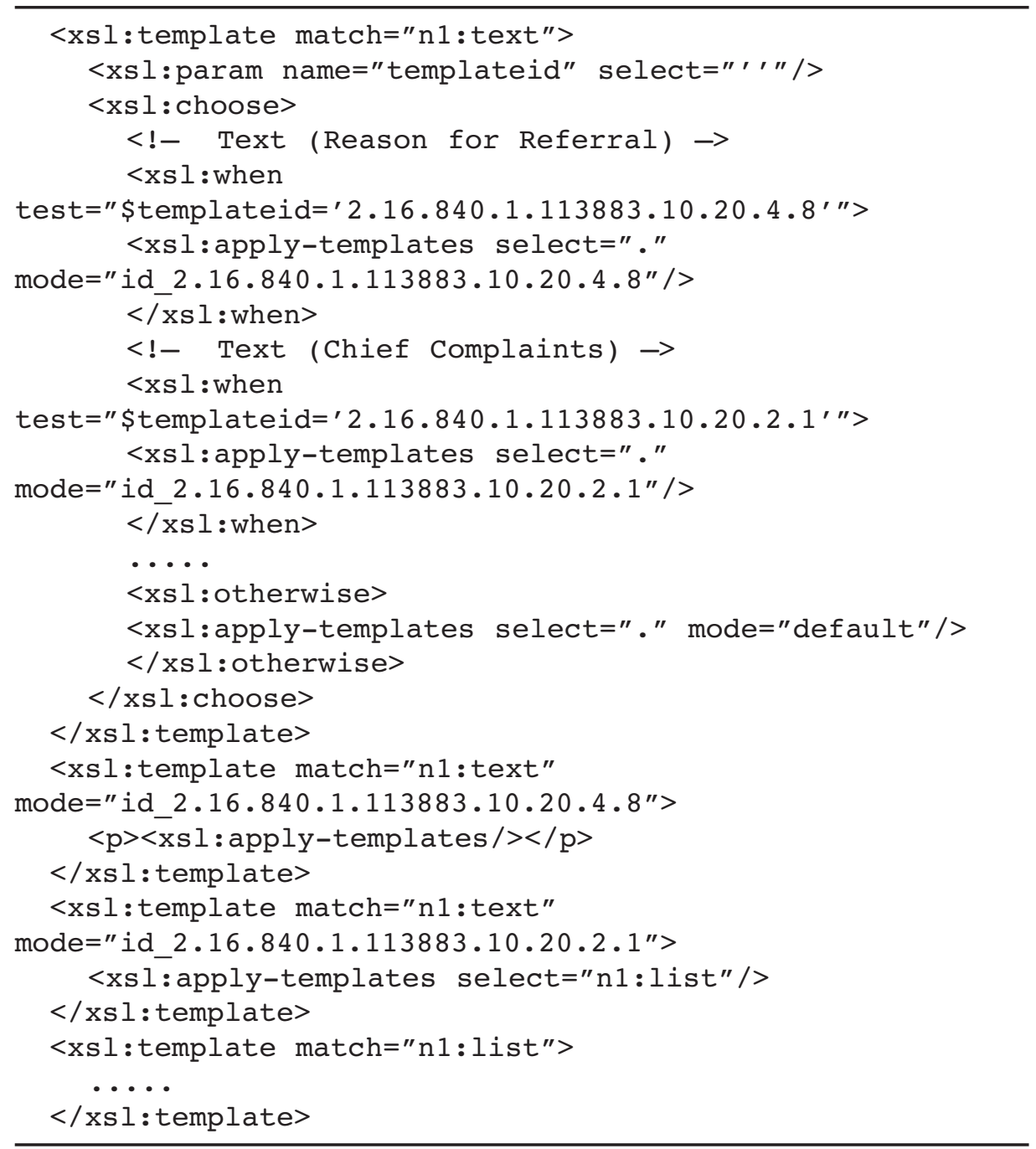




\section{E. RENDERING OF A CLINICAL DOCUMENT WITH FORM ELEMENTS AND KNOWLEDGE BASES LINKS}

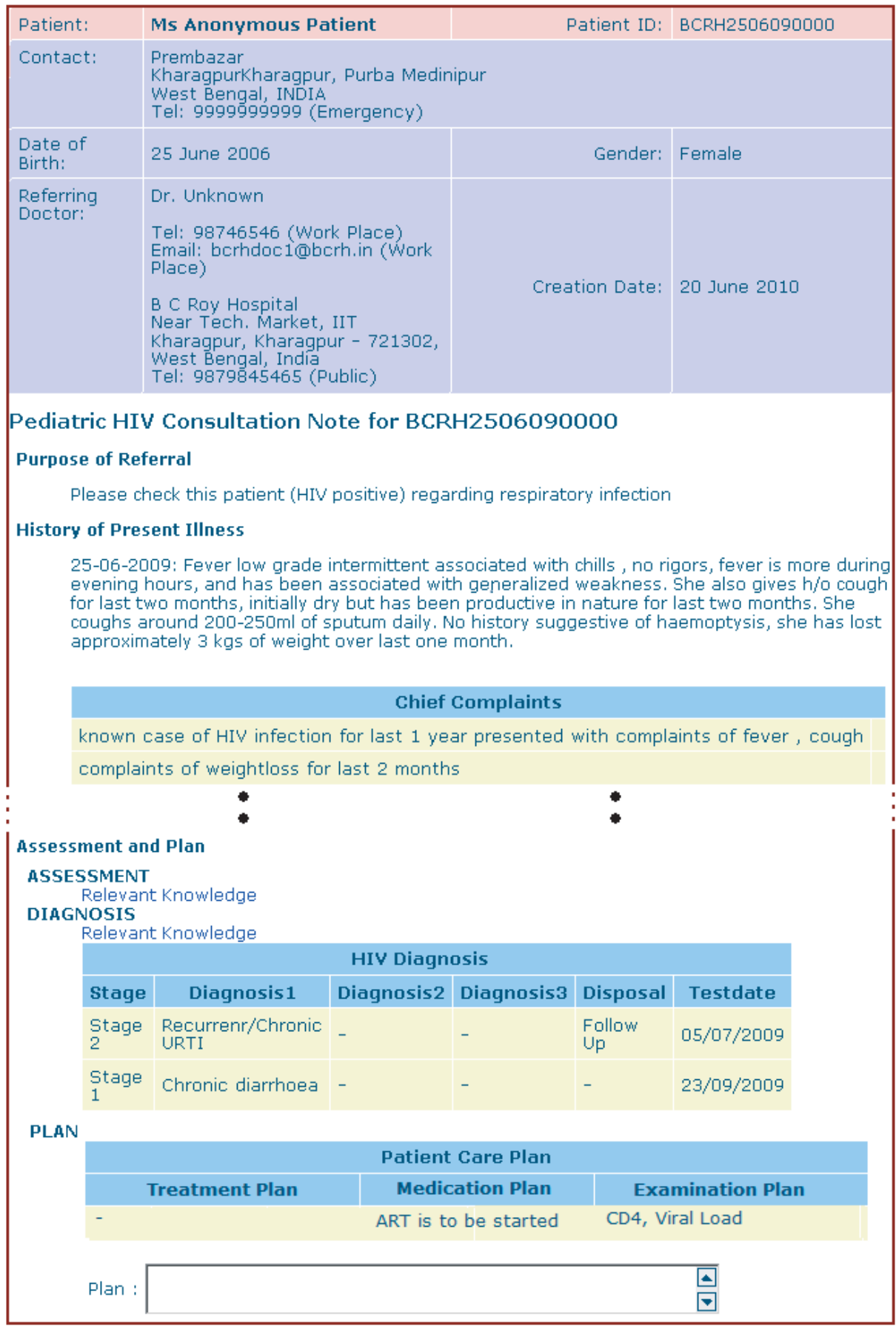




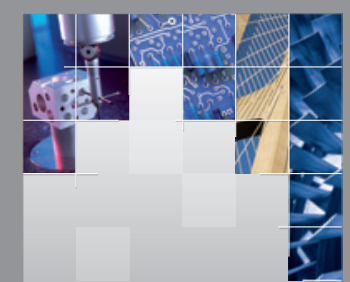

\section{Enfincering}
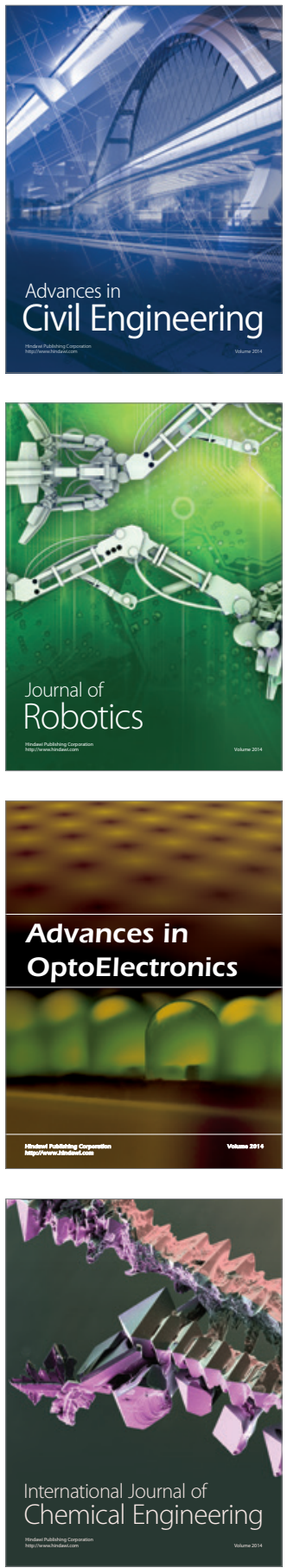

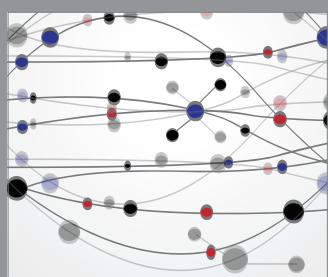

The Scientific World Journal

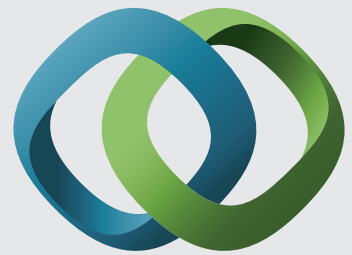

\section{Hindawi}

Submit your manuscripts at

http://www.hindawi.com
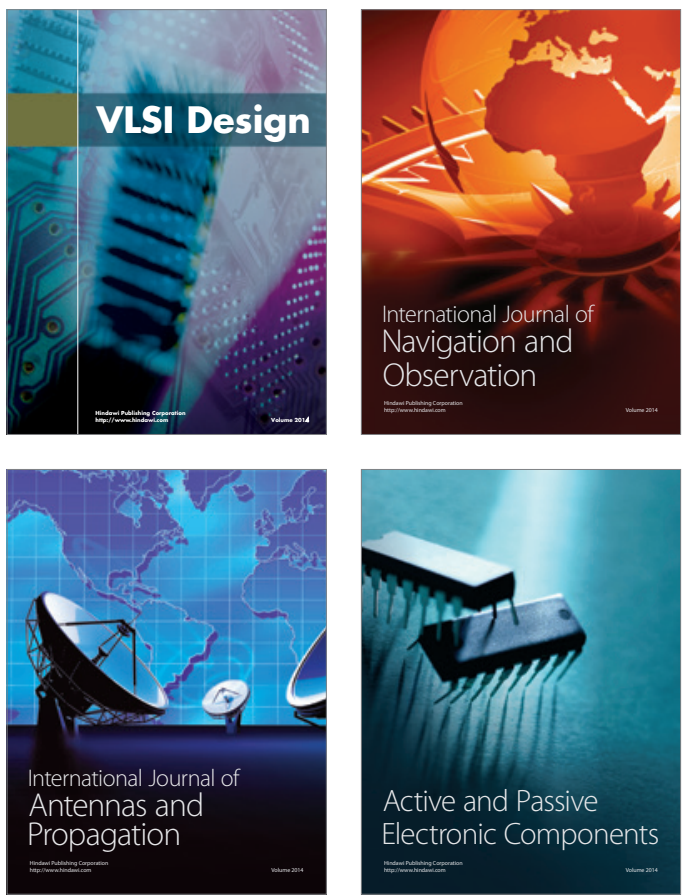
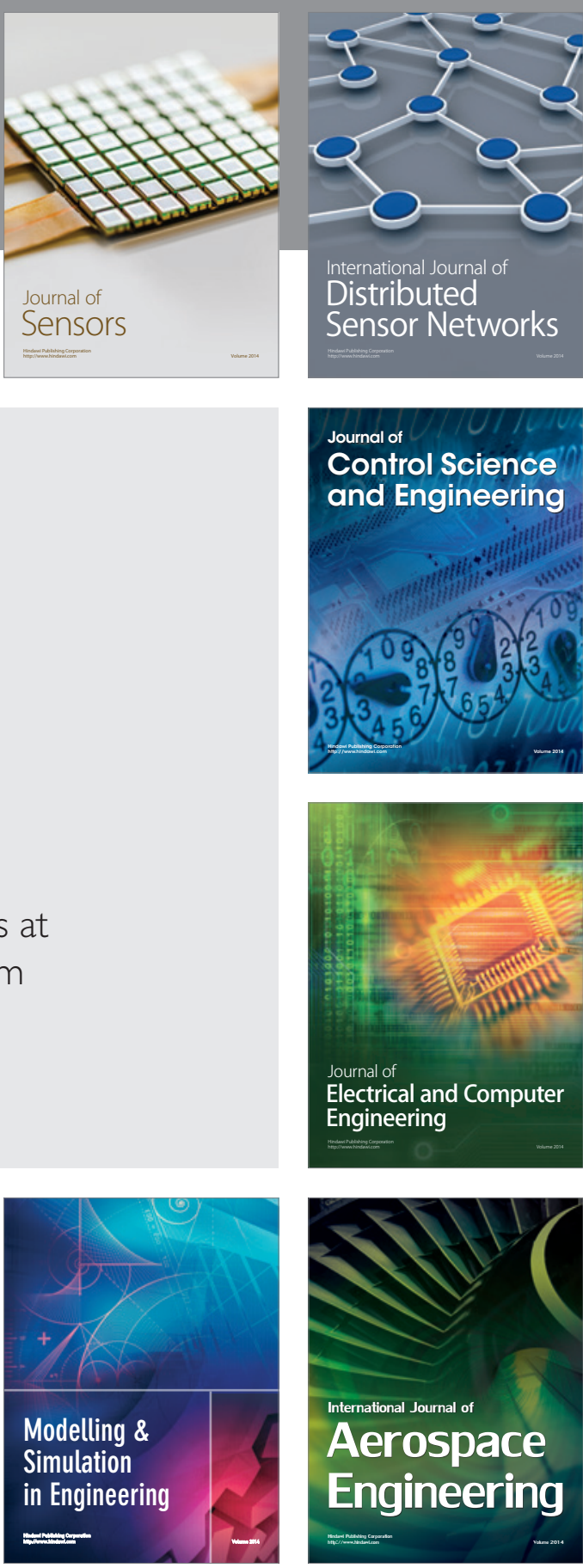

International Journal of

Distributed

Sensor Networks

Journal of

Control Science

and Engineering
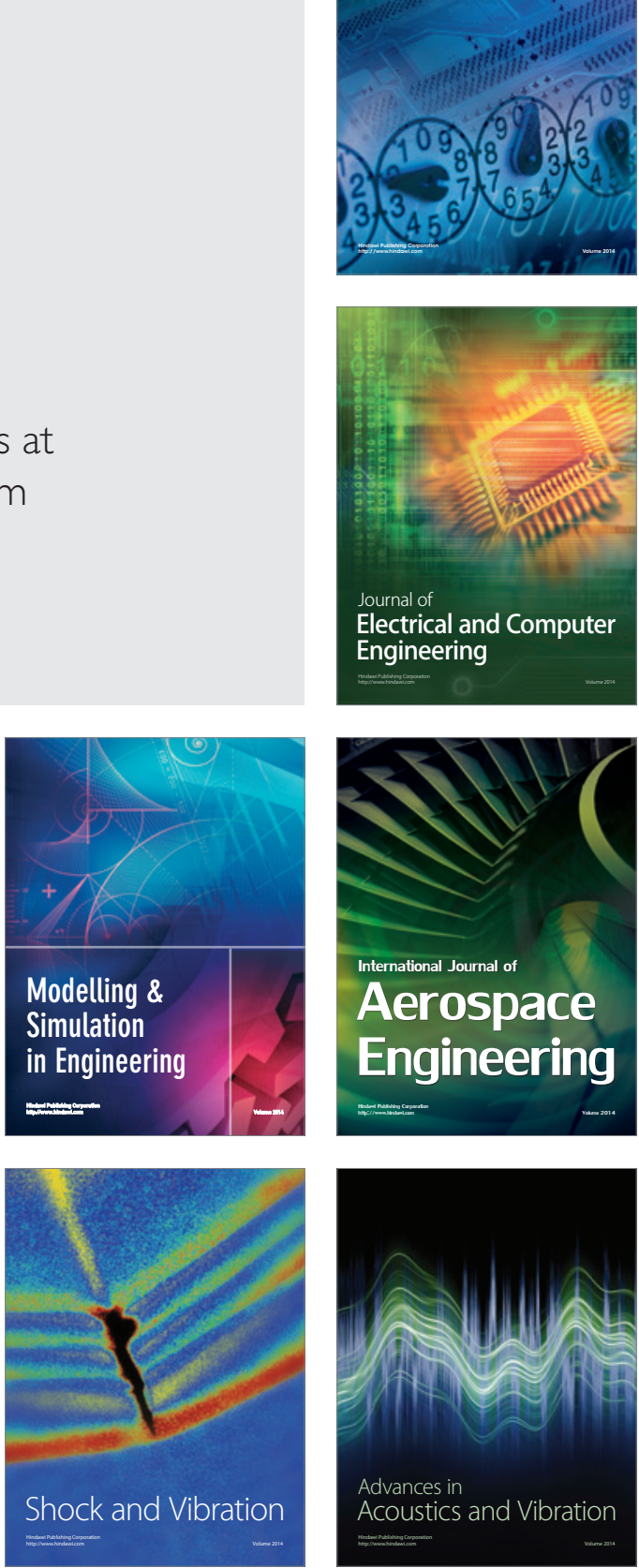